\title{
New Administrative Practice: The Organizational Identity Operation of Teacher Departments
}

\author{
Chen Yu-Chuan ${ }^{1, *}$ \\ ${ }^{1}$ Department of Education, National Taiwan Normal University, Taipei, Taiwan R. O. C. \\ *Correspondence: Department of Education, National Taiwan Normal University, Taipei, Taiwan R. O. C. E-mail: \\ a04001@ntnu.edu.tw
}

Received: June 29, 2019 Accepted: July 19, 2019 Online Published: September 19, 2019

doi:10.5430/sass.v6n2p77 URL: https://doi.org/10.5430/sass.v6n2p77

\begin{abstract}
This study evaluated the organizational identity perceptions of teachers in teacher departments. Based on a literature review, this research regards organizational identity as being composed of mind identity, behavior identity, and visual identity. Fieldwork was conducted, and 180 students in teacher departments were asked to participate in the study. After valid questionnaires were received, SPSS 22.0 was used for analysis. Importance and performance analysis (IPA) is a strategic tool that was used in this study to capture staff requirements for achieving high satisfaction and allocating resources in teacher departments. There were eight, eight, two, and two attributes in Quadrants I, II, III, and IV, respectively. The results of this study could be useful for policymakers and scholars. Policymakers could learn from the IPA results and the prioritized variables, and researchers could gain a better understanding of the organizational identity of universities.
\end{abstract}

Keywords: organizational identity, teacher department, university, Taiwan

\section{Introduction}

A country's economic development largely depends on the quality of its teacher cultivation. In Taiwan, teachers are educated in departments of teacher education or other centers for teacher education. Therefore, teacher departments play an important role in training high-quality school teachers. Training high-quality school teachers for elementary and secondary schools is an important objective of teacher departments. Students studying to be teachers take both required and elective courses, and after they fulfill their course requirements, they must undertake six months of teaching practice in schools. Taiwan's declining birth rate is affecting school enrolment, including kindergartens and elementary, secondary, and high schools. This decline also means fewer people are interested in pursuing careers as teachers, and university teacher departments are finding it hard to recruit students. Therefore, the work of attracting excellent students has become an important task.

In many countries, higher education (HE) has progressed from being a niche service consumed by a small elite to a mass-market service in which increasing numbers of students are catered to by an increasing number of diverse providers (O’Neill \& Palmer, 2004). An increasingly market-driven HE sector is forcing managers to think about how to use business theories and strategies. The subject of organizational operation has received increasing attention, following the management theories established by business industries. Organizational identity is an important issue in business industries. Briggs, Jaramillo, and Weeks (2012), for example, tested a model involving ethical climate, organizational identity comparisons, lone-wolf tendencies, life satisfaction, behavioral performance, and outcome performance among salespeople. Many empirical studies have also found that universities are undoubtedly changing due to both internal developments and external dynamics (Stensaker, 2014). Stensaker (2014) noted that organizational identity is a relatively new concept in HE research. However, it is an important concept for understanding university dynamics.

Importance and performance analysis (IPA) is one such matrix widely used for the evaluation of products and services. IPA identifies satisfaction as the function of two components: the importance and performance of products or services (Mallya \& Patwardhan, 2018). It is a simple and effective technique that can be used to guide 
practitioners in prioritizing attributes in organizations. There has been some related research in education sectors, such as Guo and Yan (2016), Mallya and Patwardhan (2018), and Pike (2004). IPA be can used to identify satisfaction with organizational identity in the HE sector.

College teachers comprise the main body of development in colleges and universities, and their degree of organizational identity is related to the survival and development of colleges and universities (Yu \& Xiong, 2018). The present research aimed to examine the perceived importance and perceived experiences of organizational identity in teacher departments. This approach can help to identify the strengths and weaknesses of such departments. This study aimed to accomplish the following:

1. Analyze the importance-performance of mind identity in teacher departments

2. Investigate the importance-performance of behavior identity in teacher departments

3. Explore the importance-performance of visual identity in teacher departments

4. Discuss the implications of the results

\section{Literature Review}

\subsection{Organizational Identity}

The concept of identity has been at the heart of most theory and research on social and individual identity (Gioia, Schultz, \& Corley, 2000). It is also a popular and important issue in organizational behavior. Some studies have focused on identity at the organizational level. Abimbola and Kocak (2007) identified non-sector-specific brand- and reputation-based factors that distinguish successful entrepreneurs and small to medium-sized enterprises from their larger counterparts; in this way, they provided the building blocks for a theoretical (resource-based view) model demonstrating the pivotal role of organizational identity for large enterprises and small businesses in knowledge economies. Haslam, Cornelissen, and Werner (2017) examined three dominant metatheories of organizational identity grounded in social constructivist, social identity, and social actor theories. They focused on the root metaphors of framing, categorization, and personification, showing how the emphasis of each root metaphor serves to direct research along a particular path in ways that often lead to a siloing of knowledge. Aside from management, there have been studies in education, such as Stensaker (2014). Stensaker (2014) argued that organizational identity is a promising concept for studying both continuity and change in HE institutions. That study identified and described the various uses of organizational identity within universities and colleges, demonstrating the relevance of the concept for understanding the current dynamics of the HE sector.

Organizational identity is typically taken to refer to members' collective understanding of features presumed to be central and relatively permanent that distinguish the organization from other organizations (Albert \& Whetten, 1985; Gioia, Schultz, \& Corley, 2000). In the literature, scholars have viewed organizational identity-the way organizational members believe others see their organization - as the way top management would like outsiders to see the organization (Scott \& Lane, 2000). Scott and Lane (2000) suggested that when beliefs about organizational attributes become widely accepted in the public arena, they are largely taken for granted. As a result, organizational identity plays an important role in organizational management and is regarded as a part of organizational reputation, image, and performance.

Identity at the organizational level can be examined in terms of how people make sense of their organization. In this research, organizational identity is understood as comprising mind identity, behavior identity, and visual identity. Mind identity includes organizational values, principles, policies, and so on. Behavior identity is the solid design that provides an organization with the principles of its corporate culture, such as employees' education and rules of behavior. Visual identity can help an organization shape its different corporate identities, including name, logo, color, patterns, and so on. Some viewpoints in the organizational identity domain describe organizational identity as visual identity, notably through means such as slogans, symbols, and physical facilities.

\subsection{Importance and Performance Analysis}

Importance and performance analysis (IPA), first proposed by Martilla and James (1977), is a tool to help management identify the strengths and weaknesses of the organization (Wu, Tang, \& Shyu, 2009). It has been applied to different areas, becoming a useful approach to measuring respondents' opinions, as in Hartikayanti, Bramanti, and Siregar (2016); Magal, Kosalge and Levenburg (2009); Mallya and Patwardhan (2018); Park, Kim, and Lee (2016); and Wong, Hideki, and George (2011). Wong, Hideki, and George (2011) used IPA to measure e-government benefits from the user's perspective. Magal, Kosalge, and Levenburg (2009) evaluated the use of 
e-business applications among SEMs to test the robustness of IPA models and to present IPA mapping as a resource/tool for decisionmaking.

In Figure 1, the $y$-axis reports the perceived importance of attributes, and the $\mathrm{x}$-axis shows perceived performance. It is divided into four quadrants, according to performance (x-axis) and importance (y-axis). As shown in the figure, this IPA model is divided into four quadrants as follows (Jairak \& Praneetpolgrang, 2013; Mallya \& Patwardhan, 2018; Martilla \& James, 1977):

Q I: Quadrant I is labeled "keep up the good work." Attributes that fall into Quadrant I are perceived as high performance and high importance. All attributes in this quadrant have been performed well and are considered the strength of the organization. For leaders, they should maintain the good work and continue to do what they do now.

Q II: Quadrant II is labeled "concentrate here." Attributes that fall into this quadrant are perceived as low-performance areas that are of high importance. Attributes in this quadrant require more attention and resources. Leaders need to consider this a top priority since customers feel these attributes are very important but indicate low performance in the organization. Improvement efforts should be concentrated here.

Q III: Quadrant III is labeled "low priority." Attributes that fall into Q III are perceived as low importance and low performance. Thus, leaders do not need to pay more attention to this quadrant. The organization should limit the resources for all attributes in this quadrant.

Q IV: Quadrant IV is labeled "possible overkill." Attributes that fall into this quadrant are perceived as low importance and high performance. This means they are overly emphasized by the organization. More attention should be devoted to other quadrants.

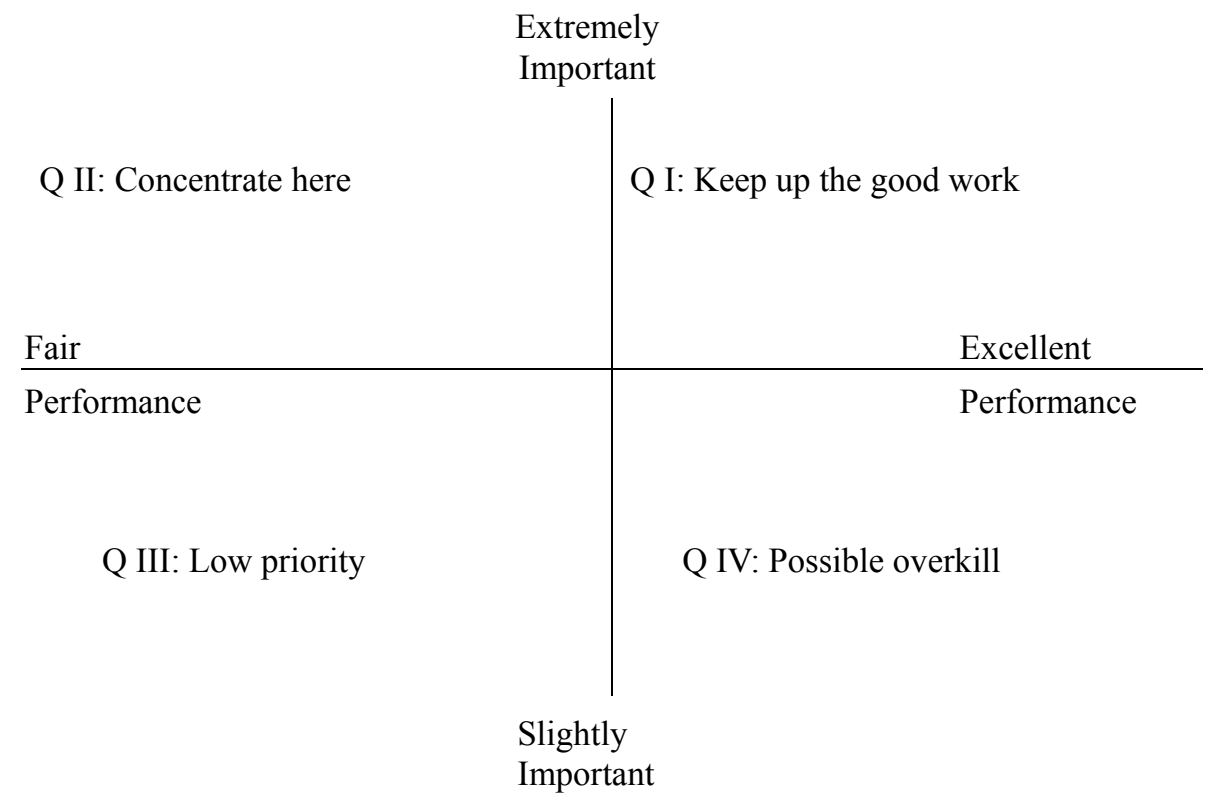

Figure 1. IPA Grid

Source: Modified from Martilla and James (1977).

IPA has been applied to both the business environment and the education sector. Numerous studies have focused on the adoption of IPA in HE (Mallya \& Patwardhan, 2018). Eun, In, and Mi (2017) used IPA to examine the tasks of nutrition teachers and dietitians in elementary, middle, and high schools in the three categories of foodservice operation, nutrition, and dietary life education. Mallya and Patwardhan (2018) used IPA to evaluate the quality of college library services to identify key areas for improvement to enhance overall user satisfaction. O'Neill and Palmer (2004) used IPA to pinpoint service failures and to direct continuous quality improvement efforts, which are of demonstrated importance to students in the HE sector. IPA has therefore been shown to be a useful tool for HE research. 


\section{Research Method}

\subsection{Selection of Variables}

This study used a 20-item questionnaire with five-point Likert scales. The determinants of organizational identity in teacher departments were selected based on the literature review. This study elected to focus on three attributes: mind identity, behavior identity, and visual identity, which are defined as follows:

1. Mind identity: Mind identity (MI) is the basis of the organization and consists of the organizational concept, vision, strategy, and so on. There are seven items in this factor, such as "To know department goals," "To reach consensus on department goals," "To have a definite development direction," and "To hire teachers in accordance with department development."

2. Behavior identity: Behavior identity (BI) is the solid design that provides an organization with the principles of its corporate culture, such as employees' education and rules of behavior. There are five items in the BI factor: "To enhance interaction among teachers," "To provide strategies to improve teacher teaching skills," "To provide strategies to improve teacher research performance," "To use many communication channels," and "To raise the staff's department identity through many activities."

3. Visual identity: Visual identity (VI) can help an organization shape its different corporate identities, including name, visual design, logo shape, colors, and so on. There are eight items in the VI factor, including "To have department songs or slogans," "To have a distinctive building or equipment," "To have educational environment decorations," and "To have a holistically designed sign."

\subsection{Data Collection and Analyses}

The fieldwork was conducted by administering the questionnaire in the respondents' native language. From the 180 students in teacher departments asked to participate in the study, nine were excluded because of incomplete answers. After 171 valid questionnaires were received, SPSS 22.0 was used for analysis. Descriptive and inferential statistics were used for all items in the questionnaire. Inferential statistics such as paired-sample t-tests were used to test the differences between importance and performance cognition.

\subsection{Sample and Questionnaire}

Three hundred questionnaires were administered, and 171 valid ones were received, constituting a $57 \%$ response rate; $51.5 \%$ of the respondents were male $(n=88)$, and $48.5 \%$ were female $(n=83)$. Of the 171 respondents who indicated their academic position, $33.3 \%$ were professors, $41.5 \%$ were associate professors, and $25.1 \%$ were assistant professors. Respondents' ages ranged from 31 years to over 61 years, with most in the ranges of $41-50(41.5 \%)$ and 51-60 (39.2\%). Twenty-five respondents were 31-41 while only nine were over 61 . No respondents were younger than 30 years old. The job tenure of most respondents ranged from 10 to 20 years $(32.2 \%)$, and $28.1 \%$ had worked in universities for 21-30 years.

The instrument was divided into two sections: Section I concerned students' perceptions of the importance and performance of organizational identity in teacher departments. Organizational identity comparisons were measured using the three dimensions of mind identity, behavior identity, and visual identity. All multi-item measures employed five-point scales, with $5=$ "strongly agree/strongly important" and $1=$ "strongly disagree/strongly unimportant." Section II collected general demographic information such as gender, age, job tenure, and so on.

\subsection{Validity and Reliability Analysis}

First, validity analysis was performed. Following exploratory factor analysis, reliability analysis was conducted.

\subsubsection{Validity Analysis}

Costello and Osborne (2005) suggested that factor analysis is preferable to principal components analysis, which had become common decades ago. The aim of factor analysis is to reveal any latent variables that cause the manifest variables to covary. This study used factor analysis to explore organizational identity. The Kaiser-Meyer-Olkin (KMO) test is a measure of how suited research data is for factor analysis. High values (close to 1.0) generally indicate that factor analysis may be useful with the research data. KMO values between 0.8 and 1 indicate that the sampling is adequate. The KMO value of .885 indicated that the sampling was adequate in this research. Bartlett's Test of Sphericity is another measure of sampling adequacy that is recommended for checking the case-to-variable ratio in the analysis. For factor analysis to be considered suitable, Bartlett's Test of Sphericity must be less than 0.05 . In this research, the significance level had a small value (less than .05), indicating that factor analysis was useful for the data. 
Many peer-reviewed educational and psychological measurement journals now ask that studies use multiple extraction techniques in order to be considered suitable for publication. These include Kaiser's criteria (eigenvalue $>$ 1 rule), the Scree test, the cumulative percentage of variance extracted, and parallel analysis (Williams, Onsman, \& Brown, 2010). It is suggested that multiple approaches should be used in factor extraction. In factor analysis, a factor loading below 0.5 is unacceptable. Three factors were produced in this research. There are seven items in factor one, called "mind identity"; the factor loadings were between 0.566 and 0.790 . There are five items in factor two, called "behavior identity"; the factor loadings were between .614 and .856. Factor three, called "behavior identity," has eight items; the factor loadings were between .571 and .824 (see Table 1).

Table 1. Factor Analysis Results of the Rotated Component Matrix

\begin{tabular}{lccc}
\hline Variable item & \multicolumn{3}{c}{ Rotated component matrix } \\
\cline { 2 - 4 } & Factor 1 & Factor 2 & Factor 3 \\
\hline To know department goals & .042 & .772 & .167 \\
To reach consensus on department goals & -.009 & .710 & .367 \\
To have a definite development direction & .104 & .773 & .228 \\
To hire teachers in accordance with department development & .062 & .790 & .177 \\
Teacher education is an important job in departments & .220 & .602 & .229 \\
Improving student learning effectiveness is important & .225 & .566 & .410 \\
The department should be named in accordance with the & .462 & .586 & -.042 \\
department development direction & .386 & .228 & .692 \\
To enhance interactivity among teachers & .141 & .255 & .856 \\
To provide strategies to improve teacher teaching skills & .126 & .287 & .806 \\
To provide strategies to improve teacher research performance & .207 & .382 & .614 \\
To use many communication channels & .399 & .214 & .673 \\
To raise the staff's department identity through many activities & .657 & -.047 & .383 \\
To have songs or slogans for departments & .704 & .110 & .390 \\
To have a distinctive building or equipment & .682 & .172 & .346 \\
To have educational environment decorations & .824 & .122 & .171 \\
To have a holistically designed sign & .710 & .234 & .008 \\
To provide an official envelope or briefing format & .709 & .001 & .251 \\
To have uniforms for all staff & .644 & .056 & .102 \\
To have famous teachers in the educational field & .571 & .384 & -.006 \\
To have a practical and beautiful web page & 4.534 & 4.002 & 3.682 \\
\hline Initial eigenvalue & 22.671 & 20.012 & 18.410 \\
\%o of variance & 22.671 & 42.683 & 61.093 \\
Cumulative \% of variance & & &
\end{tabular}

\subsubsection{Reliability Analysis}

An internal consistency analysis was performed by determining the Cronbach's coefficient alpha for each factor identified (DeVellis, 2003). The Cronbach's alpha of the overall scale reliability of organizational identity/importance was .914, indicating good reliability. The Cronbach's alpha for the overall scale reliability of organizational identity/performance was .945 , also indicating very good reliability. Table 2 shows the scale reliability analysis results. The Cronbach's alpha of mind identity was .863 , behavior identity was .888 , and visual identity was .873 in the importance areas. Mind identity $(\alpha=.916)$ and behavior identity $(\alpha=.927)$ were very credible, and visual identity $(\alpha=.868)$ was credible in the performance sector. According to the reliability analysis, the questionnaire had good internal consistency and reliability.

Table 2. Cronbach's Alpha for Reliability Analysis of Scales

\begin{tabular}{cccc}
\hline Factors & & Items & Cronbach's alpha \\
\hline Mind identity & Importance & 7 & .863 \\
& Performance & 7 & .916 \\
Behavior identity & Importance & 5 & .888 \\
& Performance & 5 & .927 \\
Visual identity & Importance & 8 & .873 \\
& Performance & 8 & .868 \\
\hline
\end{tabular}




\section{Results and Analysis}

\subsection{Paired-Sample T-Tests}

The paired-sample t-tests showed significant differences between the importance and performance of organizational identity. Table 3 presents the results of the paired-sample t-tests. The mean scores for all importance items were higher than those for performance. The sig. (two-tailed) was .00, the paired-sample t-test was significantly different, and the average (mean) of importance scores was higher than that of performance scores. This means the organizational identities of teacher departments are more important than their actual performance. The largest gaps between importance and performance were found in items $8(\mathrm{MD}=.719)$ and $9(\mathrm{MD}=.813)$. Both belong to behavior identity. Item 8 is "To provide strategies to improve teacher teaching skills," and item 9 is "To provide strategies to improve teacher research performance."

Table 3. Results of Paired-Sample T-Tests

\begin{tabular}{|c|c|c|c|c|c|c|c|}
\hline \multirow{2}{*}{$\begin{array}{l}\text { Item } \\
\text { number }\end{array}$} & \multirow[t]{2}{*}{ Items } & \multirow[t]{2}{*}{ Mean } & \multirow[t]{2}{*}{ SD } & \multicolumn{2}{|c|}{ Paired sample } & \multirow[b]{2}{*}{ t-test } & \multirow{2}{*}{$\begin{array}{c}\text { Level of } \\
\text { significance } \\
\text { (two-tailed test) }\end{array}$} \\
\hline & & & & $\begin{array}{c}\text { Mean } \\
\text { deviation }\end{array}$ & $\begin{array}{l}\text { Standard } \\
\text { deviation }\end{array}$ & & \\
\hline \multirow[t]{2}{*}{1} & Importance & 4.63 & .541 & .538 & .777 & 9.060 & .000 \\
\hline & Performance & 4.09 & .769 & & & & \\
\hline \multirow[t]{2}{*}{2} & Importance & 4.64 & .551 & .696 & .895 & 10.167 & .000 \\
\hline & Performance & 3.94 & .879 & & & & \\
\hline \multirow[t]{2}{*}{3} & Importance & 4.59 & .550 & .673 & .938 & 9.373 & .000 \\
\hline & Performance & 3.92 & .897 & & & & \\
\hline \multirow[t]{2}{*}{4} & Importance & 4.58 & .592 & .520 & .754 & 9.025 & .000 \\
\hline & Performance & 4.06 & .820 & & & & \\
\hline \multirow[t]{2}{*}{5} & Importance & 4.52 & .689 & .322 & .749 & 5.617 & .000 \\
\hline & Performance & 4.20 & .865 & & & & \\
\hline \multirow[t]{2}{*}{6} & Importance & 4.64 & .538 & .450 & .687 & 8.566 & .000 \\
\hline & Performance & 4.19 & .762 & & & & \\
\hline \multirow[t]{2}{*}{7} & Importance & 4.19 & .754 & .550 & .869 & 8.274 & .000 \\
\hline & Performance & 3.64 & .992 & & & & \\
\hline \multirow[t]{2}{*}{8} & Importance & 4.24 & .748 & .719 & .966 & 9.740 & .000 \\
\hline & Performance & 3.52 & 1.025 & & & & \\
\hline \multirow[t]{2}{*}{9} & Importance & 4.25 & .760 & .813 & 1.000 & 10.629 & .000 \\
\hline & Performance & 3.44 & 1.012 & & & & \\
\hline \multirow[t]{2}{*}{10} & Importance & 4.49 & .617 & .474 & .835 & 7.415 & .000 \\
\hline & Performance & 4.01 & .914 & & & & \\
\hline \multirow[t]{2}{*}{11} & Importance & 4.20 & .811 & .579 & .926 & 8.178 & .000 \\
\hline & Performance & 3.63 & 1.035 & & & & \\
\hline \multirow[t]{2}{*}{12} & Importance & 3.74 & 1.099 & .263 & .980 & 3.513 & .001 \\
\hline & Performance & 3.47 & 1.160 & & & & \\
\hline \multirow[t]{2}{*}{13} & Importance & 4.05 & .960 & .596 & 1.181 & 6.604 & .000 \\
\hline & Performance & 3.46 & 1.169 & & & & \\
\hline \multirow[t]{2}{*}{14} & Importance & 4.11 & .815 & .491 & .929 & 6.914 & .000 \\
\hline & Performance & 3.62 & 1.052 & & & & \\
\hline \multirow[t]{2}{*}{15} & Importance & 4.06 & .902 & 468 & .909 & 6.728 & .000 \\
\hline & Performance & 3.60 & 1.044 & & & & \\
\hline \multirow[t]{2}{*}{16} & Importance & 4.16 & .886 & .281. & 1.036 & 3.542 & .001 \\
\hline & Performance & 3.88 & 1.084 & & & & \\
\hline \multirow{2}{*}{17} & Importance & 3.31 & 1.298 & .345 & 1.175 & 3.840 & .000 \\
\hline & Performance & 2.96 & 1.418 & & & & \\
\hline 18 & Importance & 4.14 & .910 & 246 & .803 & 3.999 & .000 \\
\hline & Performance & 3.89 & .933 & & & & \\
\hline 19 & Importance & 4.25 & .652 & .503 & .785 & 8.378 & .000 \\
\hline & Performance & 3.75 & .882 & & & & \\
\hline 20 & Importance & 4.54 & .566 & .345 & .697 & 6.471 & .000 \\
\hline & Performance & 4.19 & .828 & & & & \\
\hline
\end{tabular}




\subsection{Importance and Performance Analysis}

Importance and performance (IPA) is a strategic tool that can help leaders to understand their staffs' wants and needs and assess their satisfaction. IPA can be the best way to capture staff requirements for achieving high satisfaction and allocating resources in departments.

\subsubsection{Mind Identity}

The IPA matrix was divided into four quadrants using the mean of the importance of six attributes in the mind identity section and the mean of performance for all attributes. Figure 2 shows the average scores of importance and performance for each of the six attributes. There are two attributes in the quadrant "Keep up the good work," two attributes in "Possible overkill," and two attributes in "Lower priority." Only one attribute falls into the quadrant "Concentrate here"- "To reach consensus on department goals"- but the performance level is fairly low. The attribute with the highest priority must be dealt with first, and improvement efforts should be concentrated there.



Figure 2. IPA Model of Mind Identity

\subsubsection{Behavior Identity}

Figure 3 presents the IPA results for behavior identity. The axes indicate the grand means of importance and performance - that is, the means of all five importance performance ratings in the behavior identity section. Using grand means as a frame of reference is preferable. There is one attribute - "To provide strategies to improve teacher research performance"-in the quadrant for high importance and high performance. This means the variable was very important to the respondents while departments also seemed to have high levels of performance for this identity. In other words, leaders just need to keep up the good work in this area. The others were located in the third quadrant: low importance and performance. Leaders should not be overly concerned since those variables are not perceived as very important. 




Figure 3. IPA Model of Behavior Identity

\subsubsection{Visual Identity}

Figure 4 presents the IPA results for visual identity. The mean importance (3.979) and mean performance (3.580) values for each attribute are plotted on the importance-performance grid. Five attributes belonged to the high-importance, high-performance quadrant (i.e., "Keep up the good work"). Two attributes - "To have songs or slogans for the departments" and "To have uniforms for all staff"-were in the third quadrant (low priority). The matrix shows that departments are performing well below average regarding visual identity. Only one attribute - "To have a distinctive building or equipment"-was in the "Concentrate here" quadrant, indicating that improvement efforts should be concentrated there.

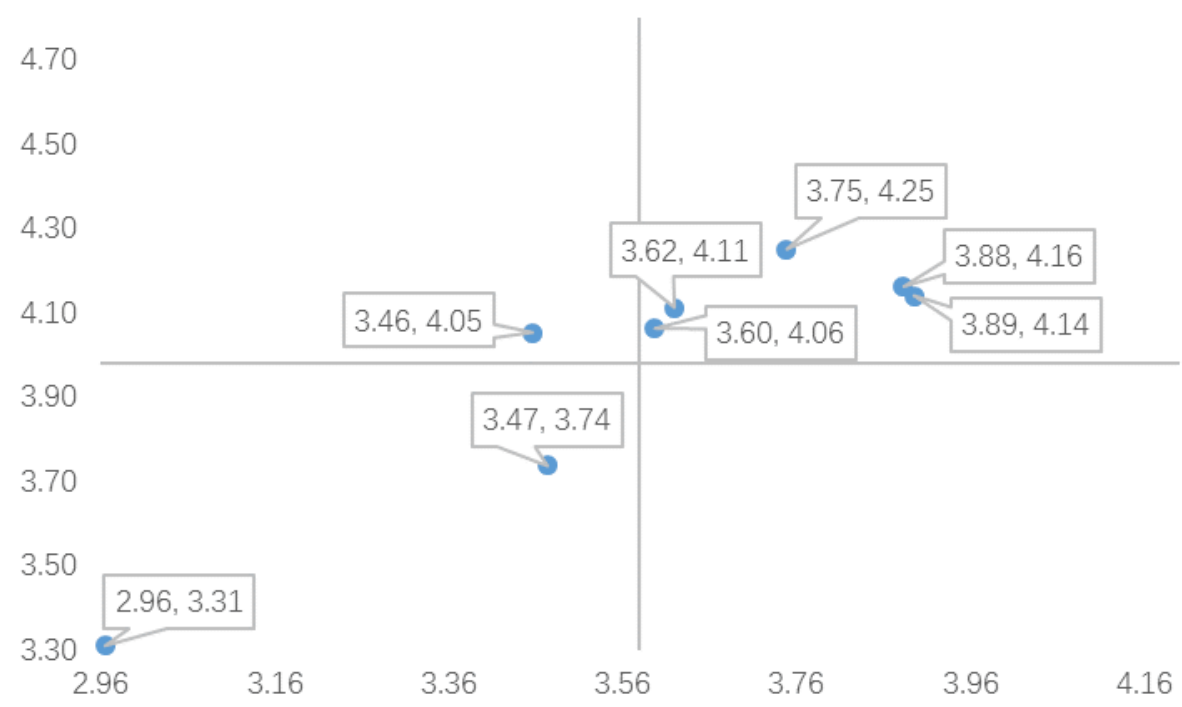

Figure 4. IPA Model of Visual Identity

\subsection{Discussion}

This research has provided further evidence of the importance and performance of the organizational identity issue while highlighting the practical value of IPA as a means of directing organizational identity improvement efforts in teacher departments. The paired-sample t-tests showed significant differences between the importance and performance of organizational identity. Among the 20 importance items, only two items' means were less than four points, including "To have songs or slogans for the departments" and "To have uniforms for all staff." Academic 
freedom is an important issue in Taiwan's universities, and many staff indicated they did not like rules and uniforms. Points for performance were low in the questionnaire. "To have songs or slogans for departments" also had less than four points, but points in the performance section were above three points.

IPA is a powerful evaluation tool that enables practitioners and academics to find attributes that are well practiced, need improvement, or are over-performed (Wong et al., 2009). In this research, IPA was used to evaluate organizational identity, including mind identity, behavior identity, and visual identity. All 20 attributes were located in four quadrants. Eight attributes fell into Quadrant I, indicating high performance and importance. These included "To know department goals," "Improving student learning effectiveness is important," "To provide strategies to improve teacher research performance," and "To have famous teachers in the educational field." In these areas, departments just need to keep up the good work.

There were eight attributes in Quadrant III ("low priority"). Four of the five attributes of behavior identity fell into this quadrant. They are perceived as having both low importance and performance and included "To have a definite development direction," "To hire teachers in accordance with department development," and "To provide an official envelope or briefing format." If resources are constrained, leaders should limit resources for attributes in this quadrant.

Finally, there were two attributes in Quadrant II and two in Quadrant IV. Quadrant IV is "Possible overkill." "To have a practical and beautiful web page" and "Teacher education is an important job in the departments" fell into Quadrant IV. Both belong to mind identity. Two attributes - "To reach consensus on department goals" and "To have a distinctive building or equipment"-fell into Quadrant II ("Concentrate here"). They are perceived as low performance and high importance. Leaders, therefore, need to consider those as top priorities. For mind identity, leaders need to reach consensus on department goals in teacher departments. For visual identity, having a distinctive building or equipment is an important brand strategy, and improvement efforts should be concentrated here.

\section{Conclusion, Suggestions, and Future Research}

\subsection{Conclusion}

This research aimed to clarify the conceptual domains and practical aspects of organizational identity in teacher departments. The results highlight the importance of organizational identity in teacher departments and support the concept of organizational identity. Factor analysis was used to explore organizational identity, which was taken to be made up of three identities: mind, behavior, and visual identity.

The mind, behavior, and visual strategies of teacher departments are important for forming organizational identity. The paired-sample t-tests showed significant differences between the importance and performance of organizational identity. Questionnaire scores for importance items were higher than for performance items, which means the organizational identities of teacher departments were more important than their actual performance. Thus, those departments have room to improve their organizational identities in the future.

The IPA results showed that leaders can understand their staff's wants and needs and assess their satisfaction. Two attributes fell into Quadrant II ("Concentrate here") - "To reach consensus on department goals" and "To have a distinctive building or equipment"- meaning leaders should focus on those as top priorities.

\subsection{Suggestions and Future Research}

As government funding decreases and the number of universities increases, HE institutions are finding themselves adopting business practices such as branding. This study has implications for teacher departments in the process of educational reform. The IPA results can help managers identify which attributes should be improved to increase teacher satisfaction. Based on the aforementioned results, managers need to apply more resources toward reaching consensus on department goals and building distinctive buildings or equipment. Reaching consensus on department goals is an important job. Teacher departments face challenges in policy reform processes. To build a common goal is a management strategy that can guide the direction of department development. Then, representative equipment or buildings can market those departments.

This research supports adopting IPA as a framework for evaluating teachers' satisfaction in terms of organizational identity. Such a framework can be used in future research on students' satisfaction. Future research can also use qualitative methods - participant observation, for example - to provide in-depth descriptions and interpretations of this topic in universities. Moreover, future empirical research should investigate how changing conditions affect staffs' perceptions of their departments. Finally, a cross-national study of organizational identity could be a creative 
and interesting avenue, presenting a deep issue for further investigation.

\section{References}

Abimbola, T., \& Kocak, A. (2007). Brand, organization identity and reputation: SMEs as expressive organizations: A resources-based perspective. Qualitative Market Research: An International Journal, 10(4), 416-430. https://doi.org/10.1108/13522750710819748

Albert, S., \& Whetten, D. (1985). Organizational identity. In L. L. Cummings \& B. M. Staw (Eds.), Research in organization-al behavior, vol. 7: 263-295. Greenwich, CT: JAI Press.

Briggs, E., Jaramillo, F., \& Weeks, W. A. (2012). The influences of ethical climate and organization identity comparisons on salespeople and their Job performance. Journal of Personal Selling \& Sales Management, 32(4), 421-436. https://doi.org/10.2753/PSS0885-3134320402

Costello, A. B., \& Osborne, J. W. (2005). Best practices in exploratory factor analysis: Four recommendations for getting the most from your analysis. Practical Assessment Research \& Evaluation, 10(7), 1-9.

DeVellis, R. F. (2003). Scale development: Theory and applications (2nd ed.). Thousand Oaks, CA: Sage Publications.

Eun, A. P., In S. C., \& Mi, N. J. (2017). Importance-performance analysis (IPA) of foodservice operation, dietary life education, and nutrition counseling tasks of nutrition teachers and dietitians in Jeju. Korea Nutrients, 1157, 1-13. https://doi.org/10.3390/nu9101157

Gioia, D. A., Schultz, M., \& Corley, K. G. (2000). Organizational identity, image, and adaptive instability. The academy of management review, 25(1), 63-81. https://doi.org/10.5465/amr.2000.2791603

Guo, H., \& Yan, Y. (2016). A performance analysis model of the ideological and political education in colleges and universities based on the extension classification method. RISTI, E7, 226-234.

Hartikayanti, H. N., Bramanti, F. L., \& Siregar, I. W. (2016). Applying importance-performance analysis for improving empowerment of cooperative in cimahi. Review of Integrative Business and Economics Research, 5(2), 196-214.

Haslam, S. A., Cornelissen, J. P., \& Werner, M. D. (2017). Metatheories and metaphors of organizational identity: Integrating social constructionist, social identity, and social actor perspectives within a social interactionist model. International Journal of Management Reviews, 19(3), 318-336. https://doi.org/10.1111/ijmr.12150

Jairak, K., \& Praneetpolgrang, P. (2013). Applying IT governance balanced scorecard and importance-performance analysis for providing IT governance strategy in university. Information Management \& Computer Security, 21(4), 228-249. https://doi.org/10.1108/IMCS-08-2012-0036

Magal, S. R., Kosalge, P., \& Levenburg, N. M. (2009). Using importance performance analysis to understand and guide e-business decision making in SMEs. Journal of Enterprise Information Management, 22(1), 137-151. https://doi.org/10.1108/17410390910932795

Mallya, J., \& Patwardhan, V. (2018). Hospitality students' perception of college library service quality: Importanceperformance analysis. DESIDOC Journal of Library \& Information Technology, 38(2), 125-131. https://doi.org/10.14429/djlit.38.2.11449

Martilla, J. A., \& James, J. C. (1977). Importance-performance analysis. Journal of Marketing, 41(1), 77-79. https://doi.org/10.1177/002224297704100112

O'Neill, M. A., \& Palmer, A. (2004). Importance-performance analysis: A useful tool for directing continuous quality improvement in higher education. Quality Assurance in Education, 12(1), 39-52. https://doi.org/10.1108/09684880410517423

Park, S. K., Kim, T., \& Lee, B. G. (2016). Applying importance performance analysis (IPA) to exam consumer behavior in multi-channel environment. Information, 19(2), 397-404.

Pike, S. (2004). The use of repertory grid analysis and importance-performance analysis to identify determinant attributes of universities. Journal of Marketing for Higher Education, 14(2), 1-18. https://doi.org/10.1300/J050v14n02_01

Scott, S. G., \& Lane, V. R. (2000). A stakeholder approach to organizational identity. Academy of Management 
Review, 25(1), 43-62. https://doi.org/10.5465/amr.2000.2791602

Stensaker, B. (2014). Organizational identity as a concept for understanding university dynamics. High Education, 69, 103-115. https://doi.org/10.1007/s10734-014-9763-8

Williams, B., Onsman, A., \& Brown, T. (2010). Exploratory factor analysis: A five-step guide for novices. Journal of Emergency Primary Health Care, 8(3), 1-13. https://doi.org/10.33151/ajp.8.3.93

Wong, M. S., Hideki, N., \& George, P. (2011). The use of importance-performance analysis (IPA) in evaluating Japan's E-government services. Journal of Theoretical and Applied Electronic Commerce Research, 6(2), 17-30. https://doi.org/10.4067/S0718-18762011000200003

Wong, M. S., Fearon, C., \& Philip, G. (2009). Evaluating e-government in Malaysia: an importance-performance grid analysis (IPA) of citizens and service providers. International Journal of Electronic Business, 7(2), 105-129. https://doi.org/10.1504/IJEB.2009.024623

Wu, H. H., Tang, Y. T., \& Shyu, J. W. (2009). A case of applying importance-performance analysis in identifying key success factors to develop marketing strategies. Journal Quality and Quantity, 44(6), 1207-1218. https://doi.org/10.1007/s11135-009-9262-7

Yu, L., \& Xiong, X. Z. (2018). Research on Chinese college teachers' organization identity based on path analysis. NeuroQuantology, 16(5), 60-66. https://doi.org/10.14704/nq.2018.16.5.1239 